\title{
A RELAÇÃO ENTRE A TEMPERATURA DA SUPERFÍCIE DOS OCEANOS TROPICAIS E A DURAÇÃO DOS VERANICOS NO ESTADO DA PARAÍBA
}

\author{
HUDSON ELLEN ALENCAR MENEZES, JOSÉ IVALDO BARBOSA DE BRITO, \\ CARLOS ANTONIO COSTA DOS SANTOS, LINDENBERG LUCENA DA SILVA
}

\author{
Universidade Federal de Campina Grande - UFCG, Avenida Aprígio Veloso, 882 \\ Bodocongó, Campina Grande - PB, CEP: 58.109-970 \\ e-mail: hudsonellen@bol.com.br, carlostorm@gmail.com
}

Recebido Maio 2007- Aceito Dezembro 2007

\begin{abstract}
RESUMO
Este trabalho tem por o objetivo verificar possíveis influências das anomalias de temperatura da superfície do mar (TSM) no Pacífico Equatorial e no Atlântico Tropical durante os veranicos mais longos dentro da estação chuvosa das microrregiões do Estado da Paraíba. Foram utilizados dados de precipitação diária de postos pluviométricos distribuídos por toda a Paraíba, no período compreendido de $1^{\circ}$ de janeiro de 1963 a 31 de dezembro de 1999, de anomalias mensais de TSM na área dos niños: Niño 1+2, Niño 3, Niño 3.4 e Niño 4, e de índices mensais do Atlântico Tropical Norte e Sul, de outubro de 1962 a dezembro de 1999 da base de dados do Centro Diagnóstico do Clima da NOAA. Foram calculadas e analisadas as correlações obtidas entre as anomalias de TSM e os veranicos e gráficos que mostram a variabilidade interanual dos maiores veranicos do estado da Paraíba. Os resultados obtidos mostraram que os veranicos das microrregiões do Litoral e Brejo são mais influenciados pelas condições de anomalias de TSM sobre o Atlântico Tropical, enquanto os veranicos das microrregiões do Cariri/Curimataú e Sertão, na parte central e oeste do Estado, são influenciados pelas anomalias de TSM do Pacífico Equatorial.
\end{abstract}

Palavras-Chave: Pacífico Equatorial, Atlântico Tropical, Coeficiente de Correlação.

\begin{abstract}
RELATIONSHIP BETWEEN THE SURFACE TEMPERATURE ON THE TROPICAL OCEANS AND THE DURATION OF DRY SPELLS IN THE PARAIIBA STATE

This paper has the objective of verifying the possible influences of the anomalies of sea surface temperature (SST) in the Equatorial Pacific and in the Tropical Atlantic on the duration of the largest dry spell of the rainy season of the micro-regions of the Paraíba State. Daily precipitation data of the rain gauge stations distributed in the all sectors of Paraíba, for the period from January 1, 1963 to December 31, 1999, the monthly anomalies of SST in the area of the niños: Niño 1+2, Niño 3, Niño 3.4 and Niño 4, and monthly indices of North and South Tropical Atlantic, for the period from October, 1962 to December, 1999, obtained from the Diagnostic Center of Climate of the NOAA were used in this study. Correlations and graphs obtained between the anomalies of SST and the dry spell are analyzed. The results obtained showed that the dry spells of the micro-regions of the Coast and Swamp areas are more influenced by the conditions of anomalies of SST on Tropical Atlantic, while the dry spells of the micro-regions of Cariri/Curimataú and Interior, in the central part and west of the State are influenced by the SST of Equatorial Pacific.
\end{abstract}

Keywords: Equatorial Pacific, Atlantic Tropical, Coefficient of Correlation. 


\section{INTRODUÇÃO}

O desenvolvimento do semi-árido do Nordeste do Brasil, principalmente no estado da Paraíba, tem sido fortemente dependente da precipitação pluviométrica, e consequentemente, as suas variações provocam prejuízos econômicos e sociais à população do Estado. A Paraíba tem como características climáticas marcantes as irregularidades do seu regime de chuvas.

Foi feita uma divisão das microrregiões homogêneas do estado da Paraíba a partir das regionalizações feitas por Silva (1996), e das microrregiões brasileiras do Instituto Brasileiro de Geografia e Estatística - IBGE (2005). Usando estes procedimentos encontraram-se seis microrregiões homogêneas do ponto de vista da precipitação para o estado da Paraíba e as denominaram de microrregiões I (Litoral), II (Brejo), III (Agreste), IV (Cariri/Curimataú), V (Sertão) e VI (Alto Sertão), as quais são mostradas na Figura 1. A época do ano e o total médio de precipitação da estação chuvosa de cada microrregião são mostrados na Tabela 1.

Neste trabalho, a quadra chuvosa é sinônimo de estação chuvosa, pois considera-se esta como sendo os quatro meses consecutivos que apresentam os maiores totais quadrimestrais de precipitação pluvial. A Tabela 1 apresenta os períodos da quadra (estação) chuvosa de cada microrregião.

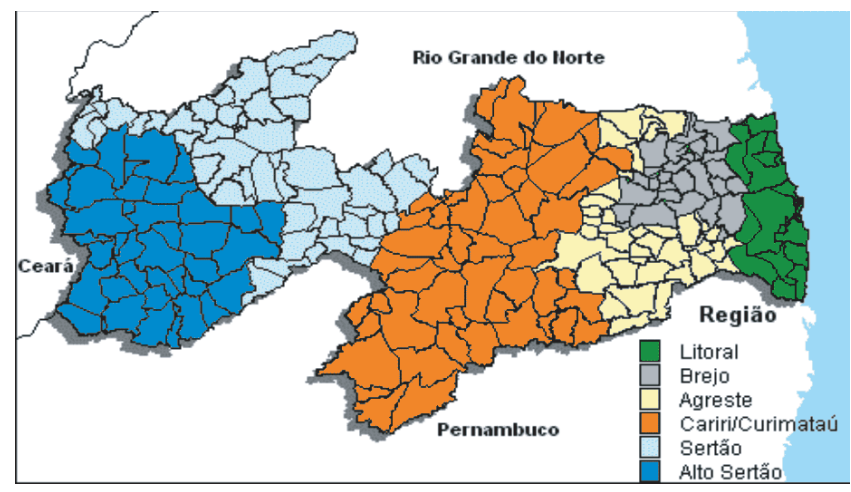

Figura 1 - Localização geográfica das microrregiões pluviometricamente homogêneas do estado da Paraíba.
A água é o insumo básico da sobrevivência de todas as espécies e indicador do desenvolvimento de uma região, sendo necessária atenção especial no seu manejo visando sua conservação em qualidade e quantidade. Isso é alcançado pela gestão dos recursos hídricos, que se refere aos procedimentos relativos à tentativa de equacionar e otimizar o seu uso (Setti et al., 2001).

A Temperatura da Superfície do Mar (TSM) nos oceanos Pacífico e Atlântico Tropicais é a principal variável física influenciadora das condições da variabilidade climática no Nordeste do Brasil (Philander, 1991). No Pacífico Tropical na presença de eventos quentes (frios) denominados de El Niño (La Niña), anomalias positivas (negativas) de TSM causam impactos climáticos diferenciados em várias áreas do Nordeste, ou seja, em períodos de El Niño, observa-se uma diminuição da precipitação pluvial no Nordeste Setentrional e um aumento nos anos de La Niña (Philander, 1991).

O ENOS (a junção do El Niño com a Oscilação Sul) e o Dipolo do Atlântico Tropical afetam diretamente o posicionamento da Zona de Convergência Intertropical (ZCIT), que por sua vez, influencia na distribuição das chuvas sobre o Nordeste. No entanto, embora a variabilidade interanual das TSM's e ventos sobre o Atlântico Tropical sejam significativamente menores do que as observadas no Pacífico Equatorial, essas variáveis afetam substancialmente a flutuabilidade do clima sobre a América do Sul, em especial a Região Nordeste do Brasil, pois a configuração de TSM e vento sobre o Atlântico Tropical são determinantes na posição da ZCIT. Alísios de sudeste mais intensos (fracos) do que os de nordeste, conjuntamente com anomalias negativas (positivas) de TSM ao sul do Equador e positivas (negativas) ao norte, acarretarão um deslocamento para o norte (sul) da ZCIT, provocando escassez (aumento) de precipitação no Nordeste Setentrional (Nobre e Shukla, 1996).

O Padrão do Dipolo no oceano Atlântico Tropical configura-se com fase positiva e negativa. A fase positiva (negativa) do Dipolo é o padrão de anomalias de TSM com sinal positivo (negativo) ao norte e negativo (positivo) ao sul

Tabela 1 - Período e precipitação média da estação chuvosa ( $\mathrm{mm} /$ estação) e precipitação anual (mm/ano) para as microrregiões pluviometricamente homogêneas do estado da Paraíba.

\begin{tabular}{ccccccc}
\hline & $\begin{array}{c}\text { Região I } \\
\text { Litoral }\end{array}$ & $\begin{array}{c}\text { Região II } \\
\text { Brejo }\end{array}$ & $\begin{array}{c}\text { Região III } \\
\text { Agreste }\end{array}$ & $\begin{array}{c}\text { Região IV } \\
\text { Cariri/ } \\
\text { Curimataú }\end{array}$ & $\begin{array}{c}\text { Região V } \\
\text { Sertão }\end{array}$ & $\begin{array}{c}\text { Região VI } \\
\text { Alto Sertão }\end{array}$ \\
\hline $\begin{array}{c}\text { Estação } \\
\text { Chuvosa }\end{array}$ & $\begin{array}{c}\text { Abril a } \\
\text { julho }\end{array}$ & $\begin{array}{c}\text { Abril a } \\
\text { julho }\end{array}$ & $\begin{array}{c}\text { Abril a } \\
\text { julho }\end{array}$ & $\begin{array}{c}\text { Fevereiro a } \\
\text { maio }\end{array}$ & $\begin{array}{c}\text { Fevereiro a } \\
\text { maio }\end{array}$ & $\begin{array}{c}\text { Janeiro a } \\
\text { abril }\end{array}$ \\
$\begin{array}{c}\text { Precipitação } \\
\text { Estação }\end{array}$ & 1036,2 & 651,1 & 436,9 & 326,2 & 575,1 & 704,0 \\
$\begin{array}{c}\text { Chuvosa } \\
\text { Precipitação } \\
\text { Ano }\end{array}$ & 1803,5 & 1174,9 & 762,1 & 484,0 & 761,8 & 926,6 \\
\hline
\end{tabular}


do equador, sendo, de um modo geral, desfavorável (favorável) à produção de precipitação sobre o norte do NEB (Moura e Shukla, 1981).

É importante mencionar que Pezzi e Cavalcanti (2001) conjeturaram que sobre condições de El Niño e Dipolo positivo no Atlântico Tropical, as precipitações ficam abaixo da média em toda a Região Nordeste, enquanto, El Niño e Dipolo negativo ocorrem chuvas acima da média no norte do Nordeste e abaixo nas demais áreas da Região. Pezzi e Cavalcanti (2001) ainda descreveram que sobre condições de La Niña e Dipolo negativo, observam-se chuvas acima da média; e La Niña com Dipolo positivo, precipitações abaixo da média em todo Nordeste. A Influência do Dipolo no Atlântico Tropical sobre as chuvas no Nordeste é mais pronunciada nos períodos de La Niña do que nos de El Niño.

Como mencionado anteriormente, a precipitação pluvial é uma variável muito importante para o desenvolvimento econômico/social da Paraíba. Portanto, o conhecimento da distribuição espacial e temporal de veranicos (fenômeno que se caracteriza por períodos de interrupção de precipitação durante a estação chuvosa) em microrregiões do Estado, bem como a influência das anomalias de TSM dos oceanos tropicais nas possíveis durações de veranicos, é de grande importância para a tomada de decisões por parte dos governos e da sociedade civil.

Este trabalho tem como objetivo verificar possíveis influências das anomalias de TSM no Pacífico Equatorial e Atlântico Tropical sobre a duração (em dias) dos maiores veranicos dentro das estações chuvosas das microrregiões do estado da Paraíba.

\section{MATERIAL E MÉTODOS}

Os dados utilizados neste trabalho consistem de séries diárias de precipitação de postos pluviométricos localizados no estado da Paraíba, pertencentes à Superintendência do Desenvolvimento do Nordeste (SUDENE), e fazem parte do acervo do Laboratório de Meteorologia, Recursos Hídricos e Sensoriamento Remoto do Estado da Paraíba (LMRS-PB). A série de cada posto tem 36 anos de dados, no período compreendido de $1^{\circ}$ de janeiro de 1963 a 31 de dezembro de 1999, com exceção do ano de 1992, o qual não tem dados confiáveis, e sendo assim desconsiderado.

Foram utilizadas anomalias mensais de TSM na área dos niños: Niño $1+2\left(0-10^{\circ} \mathrm{S}, 90^{\circ} \mathrm{W}-80^{\circ} \mathrm{W}\right)$, Niño $3\left(5^{\circ} \mathrm{N}-5^{\circ} \mathrm{S}, 150^{\circ} \mathrm{W}-\right.$ $\left.90^{\circ} \mathrm{W}\right)$, Niño $3.4\left(5^{\circ} \mathrm{N}-5^{\circ} \mathrm{S}, 170^{\circ} \mathrm{W}-120^{\circ} \mathrm{W}\right)$ e Niño $4\left(5^{\circ} \mathrm{N}-5^{\circ} \mathrm{S}\right.$, $\left.160^{\circ} \mathrm{E}-150^{\circ} \mathrm{W}\right)$ (Oliveira, 1999) (Figura 2), Índice mensal do Atlântico Tropical Norte (TNAI), que é a anomalia de TSM na área compreendida entre $5^{\circ} \mathrm{N}-23,5^{\circ} \mathrm{N}$ e $15^{\circ} \mathrm{W}-57,5^{\circ} \mathrm{W}$, e Índice mensal do Atlântico Tropical Sul (TSAI), que é a anomalia de
TSM na área compreendida entre $0-20^{\circ} \mathrm{S}$ e $10^{\circ} \mathrm{E}-30^{\circ} \mathrm{W}$ (Figura 3), de outubro de 1962 a dezembro de 1999, da base de dados do Centro Diagnóstico do Clima (CDC) da Administração Nacional do Oceano e Atmosfera (NOAA) dos Estados Unidos da América (EUA). Ressalta-se que as áreas do TNAI e TSAI correspondem à região associada ao padrão de Dipolo do Atlântico Tropical (Moura e Shukla, 1981; Servain, 1991).

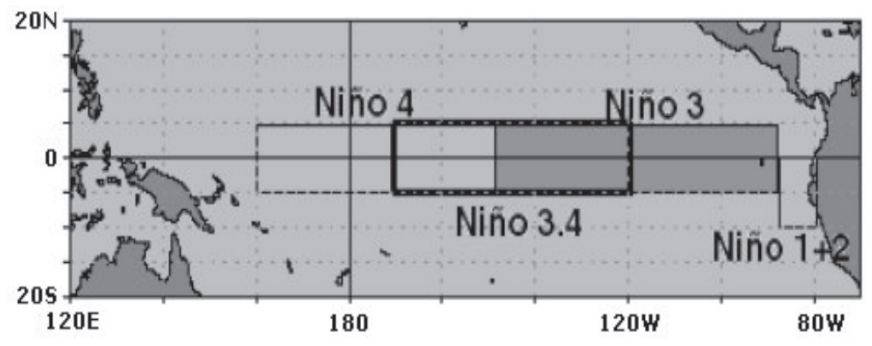

Figura 2 - Áreas do Oceano Pacífico Equatorial, Niño 1+2, Niño 3 , Niño 3.4 e Niño 4. Fonte: Oliveira (1999).

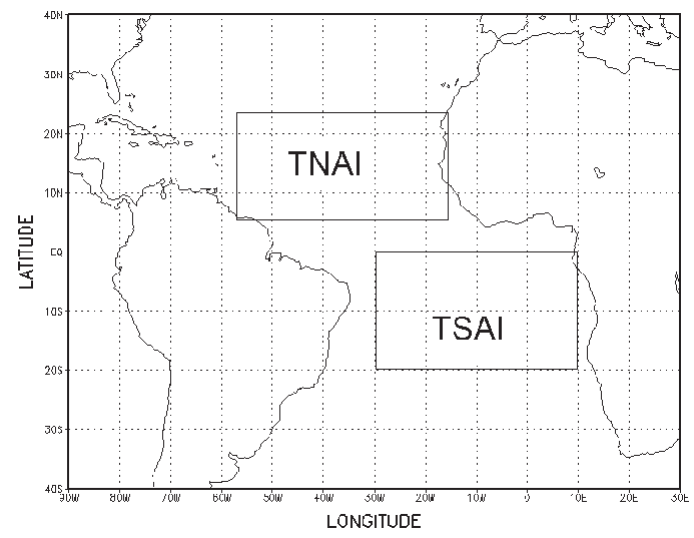

Figura 3 - Áreas do oceano Atlântico Tropical que foram calculados os TNAI e TSAI, associadas ao Padrão de Dipolo de anomalias de TSM no Atlântico.

Considerou-se veranico para cada microrregião de estudo como sendo o número de dias consecutivos em que a precipitação diária foi inferior ou igual a $2 \mathrm{~mm} / \mathrm{dia}$, em um primeiro teste, e de $4 \mathrm{~mm} / \mathrm{dia}$, em uma segunda etapa, o qual mostrou-se ser mais consistente que o primeiro valor ( $2 \mathrm{~mm} / \mathrm{dia})$. O maior veranico neste caso é o veranico mais longo da quadra (estação chuvosa).

A literatura, em geral, considera como dias secos, para efeito de estimativa de duração de um veranico, aqueles sem chuva ou com precipitação inferior a $2 \mathrm{~mm} /$ dia (Santana et al., 2005). Entretanto, isto é aplicado para localidades isoladas. Como no presente trabalho as análises são para microrregiões, optou-se por usar dois limiares, um de $2 \mathrm{~mm} / \mathrm{dia}$, recomendado pela maioria da literatura para localidade isolada, e de $4 \mathrm{~mm} / \mathrm{dia}$, por considerar uma grande área, e não uma localidade isolada. 
Ressalta-se que esse valor de $4 \mathrm{~mm} /$ dia não tem sido referidos em trabalhos sobre veranicos, pois a maioria das pesquisas sobre veranicos fazem estudos para localidades isoladas. De acordo com Fennessey e Vogel (1996), um posto pluviométrico é representativo de uma área de $16 \mathrm{~km} 2(4 \mathrm{~km}$ x $4 \mathrm{~km})$, para topografia bastante irregular, a $625 \mathrm{~km} 2(25 \mathrm{~km}$ x $25 \mathrm{~km})$, para topografia muito plana. Uma microrregião do estado da Paraíba é aproximadamente $10.000 \mathrm{~km} 2(100 \mathrm{~km}$ x $100 \mathrm{~km})$, portanto, optou-se por utilizar um segundo limiar de $4 \mathrm{~mm} / \mathrm{dia}$.

Foram utilizados 3 (três) postos pluviométricos para a microrregião do Litoral, 8 (oito) para cada uma das microrregiões do Brejo e Agreste, 10 (dez) para a microrregião do Sertão e 11 (onze) para cada uma das microrregiões do Cariri/Curimataú e Alto Sertão.

A partir da distribuição temporal dos maiores veranicos para cada microrregião do estado da Paraíba, foi estimada a relação entre os veranicos e as anomalias de temperatura da superfície do mar (ATSMs) nas áreas dos niños (Nino 1+2, Nino 3, Nino 3.4 e Nino 4), assim como na área associada ao Padrão de Dipolo (TNAI e TSAI) de anomalias de TSM do Atlântico Tropical, mostradas nas figuras 2 e 3 , respectivamente.

As relações foram estimadas fazendo uso da equação de regressão linear simples, ou seja, calculou-se o coeficiente de correlação linear de acordo com Bussab e Morettin (1987) entre as anomalias de TSM do mês de outubro do ano j e os veranicos da estação chuvosa do ano $\mathrm{j}+1$ de cada microrregião; em seguida foi feito cálculo semelhante para as anomalias de TSM do mês de novembro do ano $\mathrm{j}$ e os veranicos das estações chuvosas do ano $\mathrm{j}+1$. Repetiu-se o mesmo procedimento para as anomalias de TSM do mês de dezembro. Em seguida estimaram-se os coeficientes de correlação entre as anomalias de TSM de janeiro do ano $\mathrm{j}+1$ e os veranicos das estações chuvosas do ano $\mathrm{j}+1$, e assim sucessivamente até as anomalias de TSM do mês de maio do ano $\mathrm{j}+1$ e os veranicos das estações chuvosas do ano $\mathrm{j}+1$. Ressalta-se que para a microrregião do Alto Sertão os cálculos foram até março, que é o penúltimo mês da estação chuvosa, pois a estação chuvosa do Alto Sertão termina em abril. Para as microrregiões do Sertão e Cariri/Curimataú, os cálculos foram até abril, que também é o penúltimo mês da estação chuvosa destas microrregiões.

Também é importante mencionar, que se tem estimativa de veranico das estações chuvosas de todas as microrregiões de 1963 a 1999. Portanto, usaram-se as anomalias de TSM de outubro de 1962 a maio de 1999.

Por outro lado, um valor qualquer de um coeficiente de correlação, para uma base de dados pequena, não é garantia de que as variáveis envolvidas realmente estejam correlacionadas. Portanto, antes de tirar qualquer conclusão sobre os valores estimados dos coeficientes de correlação é necessário a aplicação de um teste estatístico para conhecer o grau real de ligação entre as variáveis analisadas. Neste trabalho optou-se pela utilização do teste estatístico $t$ de Student, por ser um teste de fácil aplicação e aceito como um teste eficiente no cômputo da significância estatística de coeficiente de correlação.

A Tabela 2 apresenta os eventos de El Niño e La Nina, bem como a intensidade com que ocorreram no período de 1963 a 1999, época em que foram estimados os veranicos.

Tabela 2 - Ocorrência de eventos de El Niño e La Niña durante o período de 1963 a 1999.

\begin{tabular}{|l|c|}
\hline Ocorrência de EI Nino & Ocorrência de La Niña \\
\hline $1963^{*}$ & $1964-1965^{* *}$ \\
\hline $1965-1966^{* *}$ & $1970-1971^{* *}$ \\
\hline $1968-1970^{* *}$ & $1973-1976^{* * *}$ \\
\hline $1972-1973^{* * *}$ & $1983-1984^{*}$ \\
\hline $1976-1977^{*}$ & $1984-1985^{*}$ \\
\hline $1977-1978^{*}$ & $1988-1989^{* * *}$ \\
\hline $1979-1980^{*}$ & $1995-1996^{*}$ \\
\hline $1982-1983^{* * *}$ & $1998-1999^{* *}$ \\
\hline $1986-1988^{* *}$ & $1999^{* *}$ \\
\hline $1990-1993^{* * *}$ & \\
\hline $1994-1995^{* *}$ & \\
\hline $1997-1998^{* * *}$ & \\
\hline$*$ evento fraco, ${ }^{*}$ evento moderado, $* * *$ evento forte. Fonte: CPTEC/ \\
INPE (2005).
\end{tabular}

A Tabela 3 apresenta os anos em que se observaram os eventos do Padrão de Dipolo no oceano Atlântico Tropical com fase positiva e negativa.

Tabela 3 - Relação dos anos em que se observaram os eventos do Padrão de Dipolo no oceano Atlântico Tropical.

\begin{tabular}{|l|l|}
\hline \multicolumn{1}{|c|}{ Fase Positiva } & \multicolumn{1}{|c|}{ Fase Negativa } \\
\hline 1966, 1970, 1978, 1979, 1980, & $\begin{array}{l}\text { 1964, 1965, 1971, 1972, 1973, } \\
\text { 1981, 1992, 1997* }\end{array}$ \\
\hline Fonte: Souza (1997), * CPC/NCEP/NOAA (2007).
\end{tabular}

\section{RESULTADOS E DISCUSSÃO}

A Figura 4a mostra a série temporal dos maiores veranicos ocorridos durante a estação chuvosa do Litoral (abril-julho) do estado da Paraíba, em que o maior foi em 1981, com um número de 25 dias consecutivos sem chuva ou com chuva abaixo de $4 \mathrm{~mm} /$ dia média para toda Microrregião. O ano de 1981 foi um ano em que houve fase positiva do Dipolo do Atlântico e normal em relação ao fenômeno El Nino-Oscilação Sul (ENOS).

Considerando veranico como sendo dias consecutivos sem chuva ou com chuvas inferiores a $2 \mathrm{~mm}$ média, o maior evento ocorreu em 1988, ano de El Niño fraco, com uma duração de veranico de 16 dias. Outros anos com duração de veranicos relativamente altos, de 14 dias, foram os de 1966, 
1976, e 1991, anos de El Niño fraco ou moderado (Tabela 2). Os menores veranicos observados para a estação chuvosa do Litoral paraibano ocorreram nos anos de 1972 e 1973, sendo o ano de 1972 um ano de El Niño e 1973 de La Niña.

Observa-se também que a série temporal de veranico considerando limiar de $4 \mathrm{~mm}$ apresenta a mesma variabilidade interanual da de $2 \mathrm{~mm}$. Como pode ser visto nas Figuras 4a e $4 b$, em que a variabilidade interanual da série com limiar de $2 \mathrm{~mm}$ segue a de $4 \mathrm{~mm}$, exceto nos anos de 1972, 1980, 1991 e 1997 na Figura 4a e os anos de 1969 e 1981 na 4b.

Observa-se na Figura 4a uma tendência de aumento da duração do veranico na microrregião do Litoral paraibano tanto no limiar de $2 \mathrm{~mm}$ como o de $4 \mathrm{~mm}$. A duração média de veranico foi de 10,0 dias para o limiar de $4 \mathrm{~mm}$ e de 7,8 dias para o de $2 \mathrm{~mm}$.

Os maiores veranicos na microrregião do Brejo paraibano ocorreram nos anos de 1976 e 1981, com 23 e 22 dias, respectivamente, para veranicos menores do que $4 \mathrm{~mm}$. Para os veranicos menores do que $2 \mathrm{~mm}$, tem-se que o menor valor foi de 4 dias e ocorreu nos anos de 1973, de La Niña moderada e 1977, normal, ambos os anos de fase negativa do Padrão de Dipolo.

Ressalta-se que na microrregião do Litoral concentrase a maior parte da população da Paraíba. Os produtos agrícolas de maior relevância são cana-de-açúcar, abacaxi e hortifrutigranjeiros, sendo este último extremamente afetado por período de veranico muito prolongado. $\mathrm{Na}$ microrregião do Brejo está concentrada a produção de frutas e avicultura. (a)

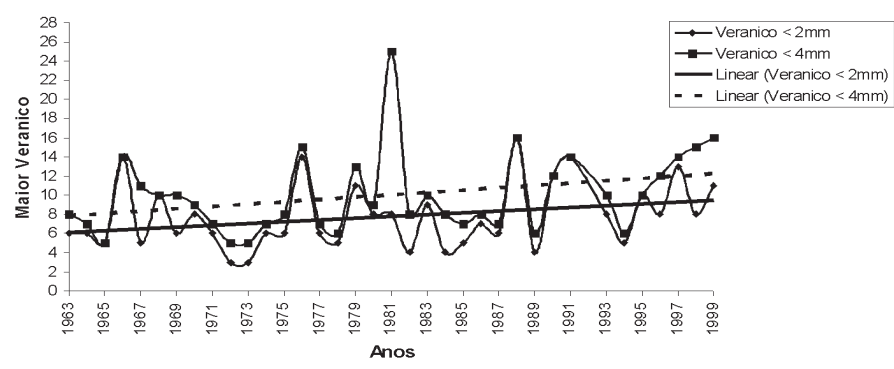

(b)

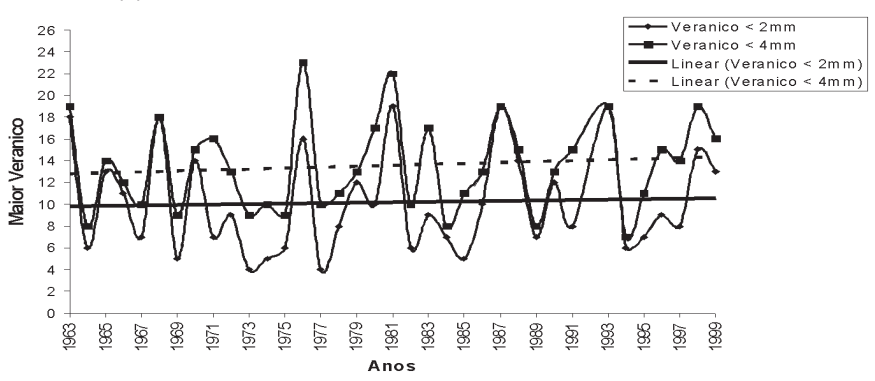

Figura 4 - Série temporal da duração em dias dos maiores veranicos ocorridos durante a estação chuvosa de abril a julho nas microrregiões do Litoral (a) e Brejo (b), para limiares menores de $2 \mathrm{~mm}$ e $4 \mathrm{~mm}$.

Na Figura 5a observa-se, que ocorreu uma tendência linear de diminuição da duração dos maiores veranicos para a microrregião do Agreste paraibano. Entretanto, uma análise visual sugere que na década de 1990 há uma tendência de aumento, principalmente no limiar de $2 \mathrm{~mm}$, e isto pode estar relacionado a diminuição das chuvas nessa década, período no qual ocorreram dois eventos de El Niño fortes.

O maior veranico ocorreu em 1980, ano normal e fase positiva do Dipolo do Atlântico, com 30 dias com chuva abaixo de $4 \mathrm{~mm}$. Para o limiar de $4 \mathrm{~mm} /$ dia a duração média é de 16,4 dias e para $2 \mathrm{~mm} /$ dia é de 11,6 dias.

Para a microrregião do Cariri/Curimataú da Paraíba, observa-se que há uma tendência linear de aumento de veranicos e que as séries temporais de veranicos apresentam a mesma flutuabilidade interanual conforme observado na Figura $5 b$.

A microrregião do Cariri/Curimataú é a que apresenta os maiores valores de veranicos das microrregiões estudadas, ultrapassando os 50 dias com chuva abaixo de $4 \mathrm{~mm}$, como foram os anos de 1980 - ano normal, 1982 - ano de El Niño forte, 1990 - ano normal e 1993 - ano de El Niño moderado, com 55, 56, 59 e 55 dias respectivamente. Além disso, há uma forte tendência linear de aumento da duração dos veranicos.
A média de veranico foi de 31,3 dias para limiar de $4 \mathrm{~mm} \mathrm{e}$ de 21,7 dias para $2 \mathrm{~mm}$. Observa-se que o limiar de $4 \mathrm{~mm} / \mathrm{dia}$ mostrou-se ser um valor muito elevado para classificação de veranico nessa Microrregião, pois com a utilização desse limiar obteve-se durações de veranicos superiores a um mês em quase todos os anos estudados. Portanto, para a microrregião do Cariri/ Curimataú recomenda-se utilizar o limiar de $2 \mathrm{~mm} / \mathrm{dia}$.

As populações do Agreste e do Cariri/Curimataú são muito afetadas por veranicos prolongados, pois estas são as microrregiões de menor precipitação total anual da Paraíba. Os veranicos destas microrregiões afetam as atividades agropecuárias, recursos hídricos e indústria e veranicos prolongados podem produzir racionamento de água para uso doméstico e industrial.

Verifica-se na Figura 6a a série temporal dos maiores veranicos durante a estação chuvosa (fevereiro-maio) da microrregião do Sertão da Paraíba, observa-se que o maior veranico foi em 1983, ano de El Niño forte, com duração de 49 dias consecutivos com chuva abaixo de $4 \mathrm{~mm}$ média para toda microrregião. Considerando-se veranico como sendo dias consecutivos sem chuva ou com chuvas inferiores a $2 \mathrm{~mm}$ média, o maior evento ocorreu também em 1983 com 48 dias de veranico. 

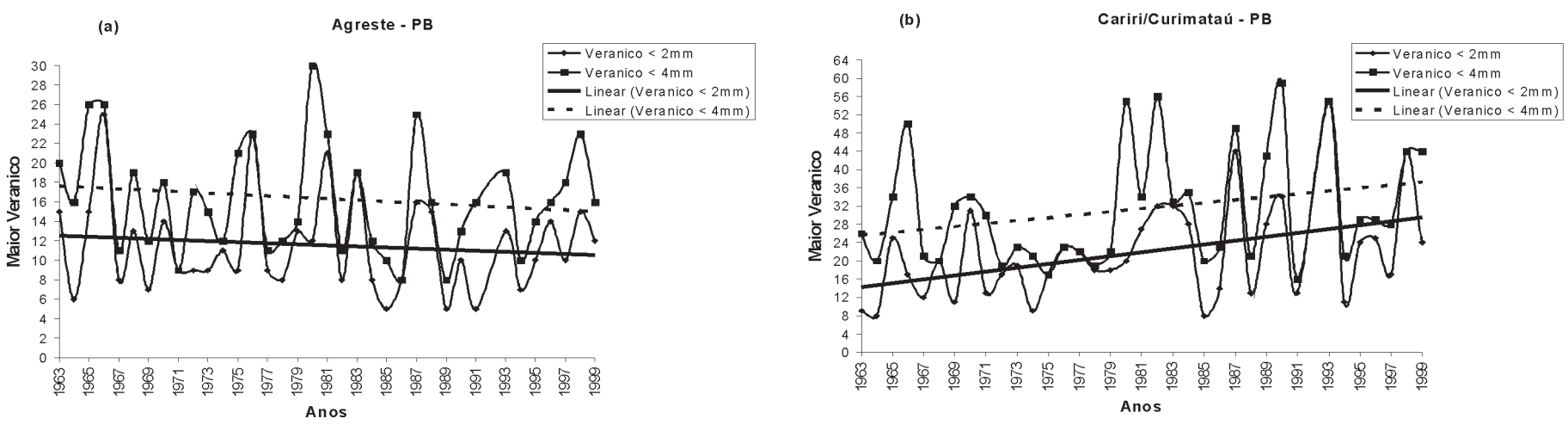

Figura 5 - Série temporal da duração em dias dos maiores veranicos, ocorridos durante as estações chuvosas de abril a julho na microrregião do Agreste (a) e de fevereiro a maio na microrregião do Cariri/Curimataú (b), para limiares menores de $2 \mathrm{~mm}$ e $4 \mathrm{~mm}$.
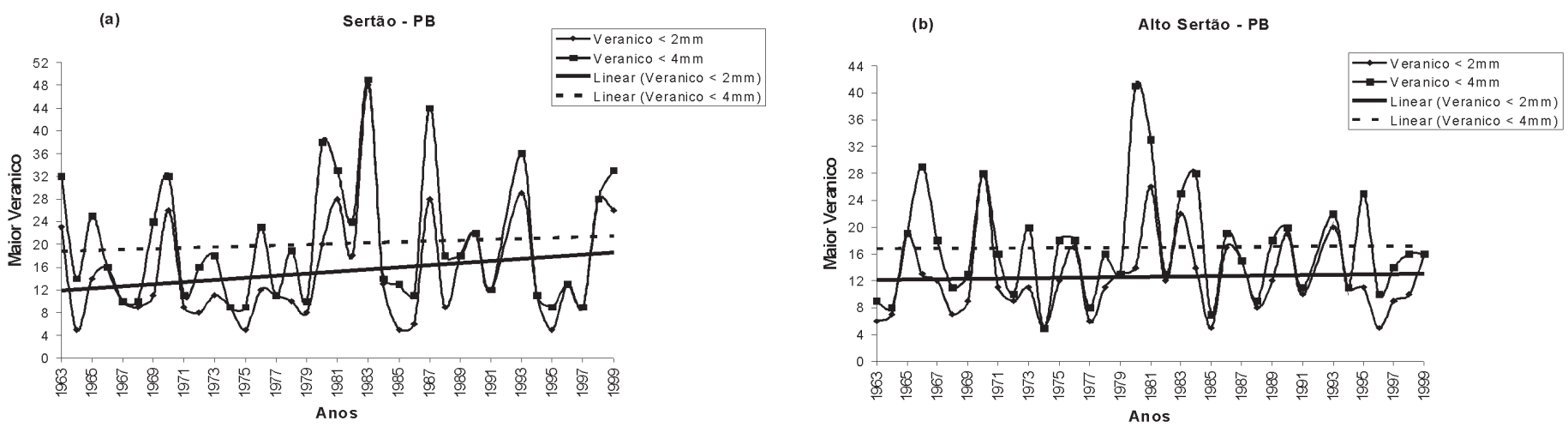

Figura 6 - Série temporal da duração em dias dos maiores veranicos, ocorridos durante as estações chuvosas de fevereiro a maio na microrregião do Sertão (a) e de janeiro a abril na microrregião do Alto Sertão (b), para limiares menores de $2 \mathrm{~mm}$ e $4 \mathrm{~mm}$.

Observa-se também, que de maneira geral, há uma mesma flutuabilidade interanual da série temporal, tanto para o veranico considerado com limiar de $2 \mathrm{~mm}$, quanto de $4 \mathrm{~mm}$ e, há uma tendência linear de aumento, principalmente para o veranico considerado com limiar de $2 \mathrm{~mm}$. A duração média para veranico de chuvas inferiores a $4 \mathrm{~mm} /$ dia foi de 20,1 dias, e para menores que $2 \mathrm{~mm} /$ dia foi de 15,1 dias.

A microrregião do Alto Sertão é a única do estado da Paraíba que apresenta a estação chuvosa de janeiro a abril. De acordo com a Figura $6 \mathrm{~b}$ pode-se observar que não há uma tendência de aumento ou diminuição de veranicos para esta Microrregião.

O ano em que ocorreu o maior veranico foi 1980 com 41 dias e chuva abaixo de $4 \mathrm{~mm} / \mathrm{dia}$. Se considerar o limiar de 2 $\mathrm{mm} / \mathrm{dia}$, o maior foi no ano de $1970 \mathrm{com} 28$ dias e chuva inferior a $2 \mathrm{~mm} /$ dia. A duração média do veranico para o limiar de 4 $\mathrm{mm} /$ dia foi de 17,0 dias e para $2 \mathrm{~mm} /$ dia foi de 12,6 dias.

Sabe-se que a precipitação total anual sobre o Estado da Paraíba é muito dependente das anomalias de TSM no Pacífico Equatorial e Atlântico Tropical. Portanto, é importante investigar se os veranicos também são influenciados pela TSM.
Para verificar a relação entre a duração dos veranicos e as anomalias de TSM no Atlântico e Pacífico Equatorial usouse os veranicos encontrados com limiar de $4 \mathrm{~mm} /$ dia, pois este limiar apresenta a mesma variabilidade interanual do limiar de $2 \mathrm{~mm} / \mathrm{dia}$, e apenas, a amplitude da variabilidade para o limiar de $4 \mathrm{~mm} /$ dia foi mais elevada. Portanto, optou-se por utilizar os veranicos obtidos com limiar de $4 \mathrm{~mm} /$ dia.

Para a microrregião do Litoral da Paraíba, obteve-se uma correlação estatisticamente significativa superior a $95 \%$ apenas o TNAI, sendo que a maior correlação foi o TNAI de outubro do ano anterior com o veranico da estação chuvosa (abril a julho) do ano seguinte (Tabela 4), ou seja, seis meses antes do início da estação chuvosa. Entretanto, esta correlação pode ser compreendida pelo fato de que outubro é o mês mais quente na área do TNAI (Uvo, 1989), a partir de novembro a TSM começa a declinar. A TSM muito quente em outubro no TNAI afetará as condições do oceano e da atmosfera nos meses seguintes, ou seja, com água mais quente que a média no Atlântico Norte, o posicionamento da ZCIT será mais ao norte do seu posicionamento normal e caminha mais lentamente em direção ao sul (Uvo, 1989). 
Portanto, a duração dos veranicos da estação chuvosa do Litoral paraibano está relacionada com o comportamento da TSM do Atlântico Tropical Norte, pois se encontrou correlações positivas estatisticamente significativas $(\alpha=0,05)$ entre os maiores veranicos da microrregião do Litoral e a TSM do Atlântico Norte, enquanto a correlação do Pacífico Equatorial não é estatisticamente significativa ao nível de $\alpha=0,10$.

Por outro lado, os maiores veranicos da microrregião do Brejo paraibano estão associados às condições dos niños $1+2$ e 3 dos meses de março a maio do $1+2$ e, abril e maio do 3, ou seja, início da estação, e do TSAI a partir de outubro do ano anterior a março do ano corrente (Tabela 5).

Realizando um estudo sobre veranico para o estado de Pernambuco, Santana et al. (2005) encontraram resultados semelhantes aos obtidos para a microrregião do Brejo, ou seja, verificaram que a região do Atlântico Tropical Sul (região do TSAI) foi a área que apresenta maior correlação entre os veranicos no período de março a junho no estado de

Tabela 4 - Coeficiente de correlação linear entre os maiores veranicos da microrregião do Litoral da Paraíba e as anomalias de TSM nas áreas dos niños, TNAI e TSAI nos meses mencionados, os valores em branco referem-se às correlações não estatisticamente significativas.

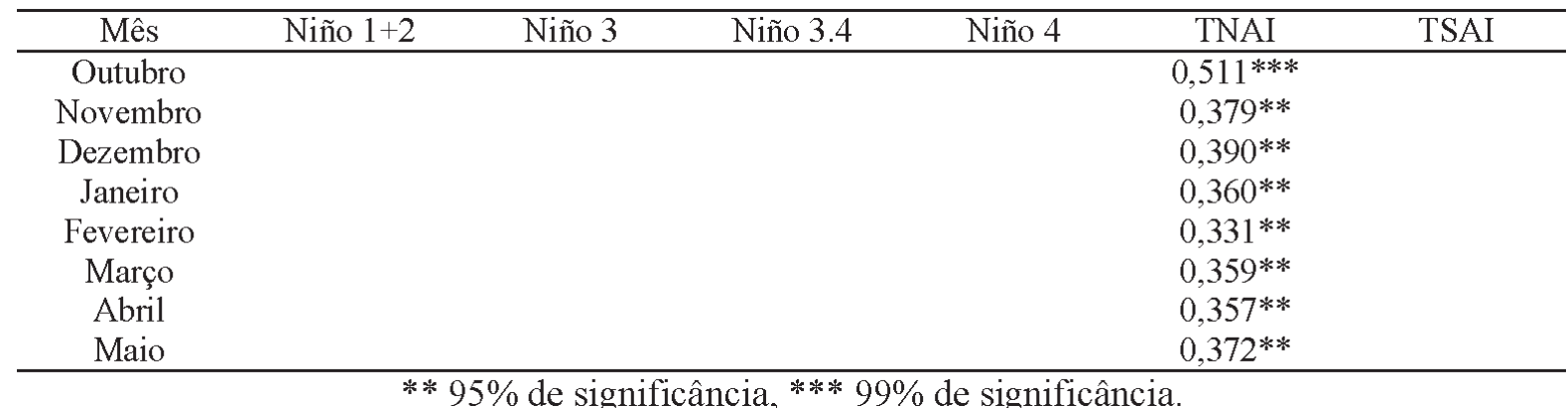

Tabela 5 - Coeficiente de correlação linear entre os maiores veranicos da microrregião do Brejo da Paraíba e as anomalias de TSM nas áreas dos niños, TNAI e TSAI nos meses mencionados, os valores em branco referem-se às correlações não estatisticamente significativas.

\begin{tabular}{ccccccc}
\hline Mês & Niño 1+2 & Niño 3 & Niño 3.4 & Niño 4 & TNAI & TSAI \\
\hline Outubro & & & & & $-0,334^{* *}$ \\
Novembro & & & & & $-0,345^{* *}$ \\
Dezembro & & & & & $-0,433^{* * *}$ \\
Janeiro & & & & & $-0,424^{* *}$ \\
Fevereiro & & & & $0,358^{* *}$ \\
Março & $0,364^{* *}$ & & & $0,304^{*}$ & $-0,328^{*}$ \\
Abril & $0,302^{*}$ & $0,339^{* *}$ & & & \\
Maio & $0,399^{* *}$ & $0,318^{*}$ & & & & \\
\hline
\end{tabular}

* 90\% de significância, **95\% de significância, *** 99\% de significância.

Tabela 6 - Coeficiente de correlação linear entre os maiores veranicos da microrregião do Agreste da Paraíba e as anomalias de TSM nas áreas dos niños, TNAI e TSAI nos meses mencionados, os valores em branco referem-se às correlações não estatisticamente significativas.

\begin{tabular}{ccccccc}
\hline Mês & Niño 1+2 & Niño 3 & Niño 3.4 & Niño 4 & TNAI & TSAI \\
\hline Outubro & & & & & & $-0,306^{*}$ \\
Novembro & & $0,303^{*}$ & & & & $-0,287^{*}$ \\
Dezembro & & & $0,314^{*}$ & & & $-0,325^{*}$ \\
Janeiro & & & $0,280^{*}$ & & & $-0,371^{* *}$ \\
Fevereiro & & & $0,336^{* *}$ & $0,324^{*}$ & $0,338^{* *}$ & $-0,404^{* *}$ \\
Março & $0,383^{* *}$ & $0,313^{* *}$ & $0,381^{* *}$ & $0,364^{* *}$ & $0,340^{* *}$ & $-0,321^{*}$ \\
Abril & $0,372^{* *}$ & $0,409^{* *}$ & $0,426^{* * *}$ & $0,284^{*}$ & $0,447^{* * *}$ & \\
Maio & $0,401^{* *}$ & & & & $0,408^{* *}$ & \\
\hline
\end{tabular}

* 90\% de significância, ** 95\% de significância, *** 99\% de significância. 
Pernambuco e as anomalias de TSM para o mesmo período, e quase não houve correlação com as áreas dos niños.

Verifica-se através da Tabela 6, que os maiores veranicos para o Agreste paraibano correlacionaram-se com o TSAI de outubro do ano anterior a março do ano corrente, negativamente, sendo que em janeiro e fevereiro a significância estatística foi $95 \%$ e nos demais meses $90 \%$. As demais áreas se correlacionam positivamente. O TNAI de fevereiro a maio apresentou correlações com significância estatística superior a 95\%, sendo abril o mês que apresentou a maior correlação de 0,447 , seguido de maio com correlação de 0,408 . Na área dos niños, a que mais se correlacionou foi o Niño 3.4, principalmente no mês de abril (correlação de 0,426). O Niño $1+2$ correlacionou-se significativamente de março a maio, sendo mais correlacionado com o mês de maio (correlação de 0,401). O Niño 3 correlacionou-se nos meses de novembro do ano anterior e março e abril (correlação de 0,409 ) do ano corrente e, o Niño 4 correlacionou-se nos meses de fevereiro a abril.

Observa-se que diferentemente das microrregiões do Litoral e Brejo, onde as correlações estatisticamente significativas sobre os veranicos se restringem ao Atlântico Tropical, os veranicos da microrregião do Agreste recebem influências tanto do Atlântico como do Pacífico (Tabela 6).

As regiões dos niños correlacionam-se positivamente com os veranicos da microrregião do Cariri/Curimataú, sendo que a maior correlação foi com o Niño 3 para o mês de abril (Tabela 7). O coeficiente de correlação linear do
TSAI não teve significância estatística para a microrregião do Cariri/Curimataú (para $\alpha<0,10$ ). De um modo geral, apesar das correlações das anomalias de TSM com os veranicos da microrregião do Cariri/Curimataú serem estatisticamente significantes, (exceto TSAI) foram relativamente baixas $(\alpha$ $>0,05)$, exceto em abril dos Niños 3 e $3.4(\alpha=0,01)$. Estes resultados estão destacados na Tabela 7 . Para esta microrregião é observado uma correlação mais marcante das anomalias de TSMs do Pacífico, principalmente, nas áreas dos niños 3 e 3.4 durante o mês de abril, enquanto estatisticamente o Atlântico praticamente não é correlacionado ao nível de significância superior a $90 \%$, exceto o mês de abril na área do TNAI.

Para o Sertão da Paraíba tem-se que as durações dos veranicos se correlacionam positivamente com os niños $1+2,3$ e 3.4 para todo o período (outubro a abril) (Tabela 8), principalmente o Niño 3 nos meses de março e abril, já dentro da estação chuvosa. O TNAI também teve correlação positiva, as quais ocorreram nos meses de março a abril, nos outros meses não se teve uma boa significância estatística. O TSAI não teve correlações significativas para o Sertão paraibano (Tabela 8).

Os veranicos da microrregião do Sertão da Paraíba estão correlacionados $(\alpha \leq 0,01)$ com as condições do Pacífico Equatorial, nas áreas dos niños 1+2, 3 e 3.4 de fevereiro a maio, e do Atlântico Tropical, TNAI de março a abril. Isto ocorre porque o principal sistema produtor de chuvas nesta Microrregião é a ZCIT, que recebe influência dos eventos El Niño e La Nina (Walker, 1928) e do Atlântico Tropical (Hastenrath e Heller, 1977).

Tabela 7 - Coeficiente de correlação linear entre os maiores veranicos da microrregião do Cariri/Curimataú da Paraíba e as anomalias de TSM nas áreas dos niños, TNAI e TSAI nos meses mencionados, os valores em branco referem-se às correlações não estatisticamente significativas.

\begin{tabular}{|c|c|c|c|c|c|c|}
\hline Mês & Niño $1+2$ & Niño 3 & Niño 3.4 & Niño 4 & TNAI & TSAI \\
\hline \multicolumn{7}{|l|}{ Outubro } \\
\hline \multicolumn{7}{|l|}{ Novembro } \\
\hline \multicolumn{7}{|l|}{ Dezembro } \\
\hline Janeiro & & & & & & \\
\hline Fevereiro & $0,294^{*}$ & $0,306^{*}$ & & & & \\
\hline Março & $0,285^{*}$ & $0,302^{*}$ & $0,303^{*}$ & $0,311^{*}$ & & \\
\hline Abril & & $0,471 * * *$ & $0,436 * * *$ & $0,284^{*}$ & $0,317^{*}$ & \\
\hline
\end{tabular}

Tabela 8 - Coeficiente de correlação linear entre os maiores veranicos da microrregião do Sertão da Paraíba e as anomalias de TSM nas áreas dos niños, TNAI e TSAI nos meses mencionados, os valores em branco referem-se às correlações não estatisticamente significativas.

\begin{tabular}{|c|c|c|c|c|c|c|}
\hline Mês & Niño $1+2$ & Niño 3 & Niño 3.4 & Niño 4 & TNAI & TNAI \\
\hline Outubro & $0,365 * *$ & $0,376^{* *}$ & $0,323^{*}$ & & & \\
\hline Novembro & $0,429 * * *$ & $0,412 * *$ & $0,344 * *$ & & & \\
\hline Dezembro & $0,411 * *$ & $0,420 * *$ & $0,388 * *$ & & & \\
\hline Janeiro & $0,411 * *$ & $0,430 * * *$ & $0,375 * *$ & & & \\
\hline Fevereiro & $0,469 * * *$ & $0,493 * * *$ & $0,444 * * *$ & & & \\
\hline Março & $0,556 * * *$ & $0,560 * * *$ & $0,508 * * *$ & $0,304 *$ & & $0,428 * * *$ \\
\hline Abril & $0,496 * * *$ & $0,602^{* * * *}$ & $0,517 * * *$ & & & $0,472 * * *$ \\
\hline
\end{tabular}

* 90\% de significância, ** 95\% de significância, ***99\% de significância. 
Tabela 9 - Coeficiente de correlação linear entre os maiores veranicos da microrregião do Alto Sertão da Paraíba e as anomalias de TSM nas áreas dos niños, TNAI e TSAI nos meses mencionados, os valores em branco referem-se às correlações não estatisticamente significativas.

\begin{tabular}{ccccccc}
\hline Mês & Niño 1+2 & Niño 3 & Niño 3.4 & Niño 4 & TNAI & TSAI \\
\hline Outubro & $0,287^{*}$ & & & & & \\
Novembro & & & & & & \\
Dezembro & & $0,283^{*}$ & $0,298^{*}$ & & & \\
$\quad$ Janeiro & & & & & & \\
Fevereiro & & & & $0,292^{*}$ & & \\
$\quad$ Março & & & & $* 00 \%$ de significância.
\end{tabular}

* 90\% de significância.

Finalmente, os maiores veranicos para a microrregião do Alto Sertão paraibano não apresentaram correlações estatisticamente significativa $(\alpha<0,10)$ com os niños, nem com o TNAI e nem com o TSAI (Tabela 9). Isto ocorre porque o principal sistema produtor de chuva para esta microrregião são os Vórtices Ciclônicos da Alta Troposfera (VCAT) (Silva, 2004), que em geral, não tem muita influencia das anomalias de TSM (Silva, 2004).

As precipitações das microrregiões do Litoral e Brejo são em grande parte, provenientes dos sistemas ondulatórios de leste, os quais têm suas origens no Atlântico Tropical (Yamazaki e Rao, 1977). Portanto, as anomalias de TSM do Atlântico estão associadas às durações dos maiores veranicos destas microrregiões. No Agreste os sistemas ondulatórios de leste também são importantes na produção de chuvas dessa Microrregião, mas a ZCIT também tem sua contribuição (Uvo, 1989). No Cariri/Curimataú, devido as suas características fisiográficas, a contribuição dos sistemas distúrbios ondulatórios de leste; da ZCIT e dos Vórtices Ciclônicos da Alta Troposfera na produção de chuva nessa microrregião é bastante irregular e vai depender da magnitude de cada um desses sistemas, no entanto a ZCIT é a que tem maior contribuição (Silva, 2004). Portanto, a relação entre a TSM no Pacífico Equatorial e os veranicos do Cariri/Curimataú é relativamente maior que a entre o Atlântico Tropical. Por outro lado, as chuvas do Sertão são muito dependentes da ZCIT e em menor grau dos Vórtices Ciclônicos (Silva, 2004). Logo, a relação da TSM no Pacífico Equatorial com a duração dos veranicos no Sertão é marcante, produzindo em muitos casos, a denominada seca verde, como em 1987. As chuvas do Alto Sertão apesar de receber influência da ZCIT são fortemente determinadas pelos Vórtices Ciclônicos (Silva, 2004). Os veranicos do Alto Sertão apresentam correlações muito baixas com as TSM tanto do Atlântico quanto do Pacífico, pois os vórtices são sistemas muito irregulares no deslocamento, na área de atuação e na magnitude.

\section{CONCLUSÕES}

A máxima duração de veranicos das microrregiões do Litoral e Brejo paraibanos é mais correlacionada com as anomalias de TSM sobre o Atlântico Tropical, enquanto a máxima duração dos veranicos das microrregiões do Cariri/ Curimataú e Sertão, na parte central e oeste do Estado, são correlacionadas com as anomalias de TSM do Pacífico Equatorial.

As durações dos veranicos na microrregião do Agreste paraibano são correlacionadas com as anomalias de TSM do Atlântico Tropical e do Pacífico Equatorial.

A relação da TSM no Pacífico Equatorial na duração dos veranicos no Sertão é marcante, produzindo, em muitos casos, a denominada seca verde, como a de 1987.

Os veranicos do Alto Sertão aparentemente não estão diretamente relacionados com as anomalias de TSM do Atlântico e do Pacífico.

De maneira geral, como mostrado nas linhas de tendência, verifica-se que ocorreu um aumento na máxima duração dos veranicos em quase todas as microrregiões da Paraíba, exceto a do Agreste.

\section{AGRADECIMENTOS}

À Unidade Acadêmica de Ciências Atmosféricas da UFCG pela disponibilidade da sua infra-estrutura; à Coordenação do Programa de Pós-Graduação em Meteorologia da UFCG; ao CNPq pela concessão de bolsa de mestrado ao $1^{\circ}$ autor e por financiar parte da pesquisa deste trabalho; aos dois revisores anônimos, que contribuíram para o aprimoramento científico deste artigo; e ao LMRS-PB por ceder os dados totais diários de precipitação das 51 localidades distribuídas em todo o estado da Paraíba.

\section{REFERÊNCIAS BIBLIOGRÁFICAS}

BUSSAB, W. O.; MORETTIN, P. A. Estatística Básica. Atual Editora Ltda, São Paulo - SP. 4ª Ed., 322p., 1987.

CPC/NCEP/NOAA. Disponível em: http://www.cpc.ncep.noaa. gov/, acessado em setembro de 2007.

CPTEC/INPE. Disponível em: http://www.cptec.inpe.br/enos/, acessado em dezembro de 2005.

FENNESSEY, N. M.; VOGEL, R. M. Regional models of 
potential evaporation and reference evapotranspiration for the northeast USA. Journal of Hydrology, v.184, n.3-4, p.337-354, 1996.

HASTENRATH, S.; HELLER L. Dynamics of climate hazards in Northeast Brazil. Quartely Journal of the Royal Meteorological Society, v. 103, n. 435, p. 77-92, 1977.

IBGE. Disponível em http://www.ibge.gov.br, acessado em outubro de 2005.

MOURA, A. D.; SHUKLA, J. On the Dynamics of Droughts in Northeast Brazil: Observations, Theory and Numerical Experiments with a General Circulation Model. Journal of the Atmospheric Science, v. 38, n. 12, p. 2653-2675. 1981.

NOBRE, P.; SHUKLA, J. Variations of Sea Surface Temperatures, wind Stress, and Rainfall over the Tropical Atlantic and South American. Journal of Climate, v. 9, n. 10, p. 24642479. 1996.

OLIVEIRA, G. S. O El Niño e Você - O Fenômeno Climático. São José dos Campos, SP: Transtec Editorial, 1999.

PEZZI, L. P.; CAVALCANTI, I. F. A. The relative importance of ENSO and Tropical Atlantic Sea Surface Temperature anomalies for seasonal precipitation over South America: A numerical study. Climate Dynamics, v. 17, n. 2-3, p. 205-212, 2001.

PHILANDER, S. G. El Niño, La Niña, and Southern Oscillation. Academic Press, Londres, 289p., 1991.

SANTANA, S. C.; LACERDA, F. F.; SIMÕES, R. S. Um Estudo da Variabilidade de Veranicos sobre o Estado de Pernambuco. In: Simpósio Internacional de Climatologia, 2005, Fortaleza-CE. Anais: CD-ROM, SBMET.

SERVAIN, J. Simple Climatic Indices for the Tropical Atlantic
Ocean and some Applications. Journal of Geophysical Research, v. 96, p. 15.137-15.146, 1991.

SETTI, A. A.; LIMA, J. E. F. W.; CHAVES, A. G. M.; PEREIRA, I. C. AGÊNCIA NACIONAL DE ENERGIA ELÉTRICA; AGÊNCIA NACIONAL DE ÁGUAS (ANA). Introdução ao Gerenciamento de Recursos Hídricos. $2^{\mathrm{a}}$ ed. Brasília, 328 p. 2001.

SILVA, M. C. L. Uso da Técnica dos Quantis para Monitoramento do Clima do Estado da Paraíba. Campina Grande, 2004, 33p. Trabalho de Conclusão de Curso de Graduação em Meteorologia - Universidade Federal de Campina Grande.

SILVA, S. T. A Influência do El Niño-Oscilação Sul na Distribuição Espacial da Precipitação no Estado da Paraíba. Dissertação de Mestrado em Meteorologia, UFCG, Campina Grande - PB, 63p, 1996.

SOUZA, E. B. Um Estudo Observacional sobre o Padrão de Dipolo de Anomalias de Temperatura da Superfície do Mar no Oceano Atlântico Tropical. Dissertação de Mestrado em Meteorologia, INPE, São José dos Campos - SP, 117p, 1997.

UVO, C. B. A Zona de Convergência Intertropical (ZCIT) e sua Relação com a Precipitação na Região Norte do Nordeste Brasileiro. Dissertação de Mestrado em Meteorologia, INPE, São José dos Campos - SP, 1989.

WALKER, G. T. Ceará (Brazil) famines and the general air movement. Beitrage Zur Physik der Frein Atmosphere, 14 (sf): 88-93. 1928.

YAMAZAKI, Y.; RAO, V. B. Tropical cloudiness over South Atlantic Ocean. Journal of the Meteorological Society of Japan, v.55, n.2, p.205-207, 1977. 